\title{
Convergence theorems for a generalized $\Phi$-pseudo-contractive type mapping in real normal linear spaces
}

Chao Wang ${ }^{1 *}$ and Li-wei Liu²

\section{"Correspondence:}

wangchaosx@126.com

${ }^{1}$ College of Mathematics and

statistics, Nanjing University of

Information Science and

Technology, Nanjing, 210044, P.R

China

Full list of author information is

available at the end of the article

\begin{abstract}
In this paper, we first give a new notion of generalized $\Phi$-pseudo-contractive type mapping, and then we consider some convergence theorems for a fixed point of the mapping. Our results improve and extend the corresponding results due to (Chidume and Chidume in J. Math. Anal. Appl. 302:545-554, 2005) and other papers.
\end{abstract}

Keywords: convergence theorems; generalized $\Phi$-pseudo-contractive type mappings; generalized $\Phi$-accretive type mappings; real normal linear spaces

\section{Introduction and statement of results}

Let $E$ be a real normed linear space and $E^{*}$ be its dual space. The normalized duality mapping $J: E \rightarrow 2^{E^{*}}$ is defined by

$$
J x=\left\{f \in E^{*}:\langle x, f\rangle=\|x\| \cdot\|f\|,\|x\|=\|f\|\right\},
$$

where $\langle\cdot, \cdot\rangle$ denotes the generalized duality pairing.

Definition 1.1 $[1,2]$ Let $\phi:[0, \infty) \rightarrow[0, \infty)$ be a function for which $\phi(0)=0, \forall r_{0}>0$, $\liminf _{r \rightarrow r_{0}} \phi(r)>0$. A mapping $T: D(T) \subset E \rightarrow E$ is called $\phi$-strongly accretive if for each $x, y \in D(T)$, there exists $j(x-y) \in J(x-y)$ such that

$$
\langle T x-T y, j(x-y)\rangle \geq \phi(\|x-y\|)\|x-y\| .
$$

We also say that $T: D(T) \subset E \rightarrow E$ is $\phi$-strongly pseudo-contractive if $I-T$ is $\phi$-strongly accretive.

Definition 1.2 Let $\Phi:[0, \infty) \rightarrow[0, \infty)$ be a function for which $\Phi(0)=0, \forall r_{0}>0$, $\liminf _{r \rightarrow r_{0}} \Phi(r)>0$. A mapping $T: D(T) \subset E \rightarrow E$ is called generalized $\Phi$-accretive if there exists $j(x-y) \in J(x-y)$ such that

$$
\langle T x-T y, j(x-y)| \geq \Phi(\|x-y\|), \quad \forall x, y \in D(T) .
$$

We also say that $T: D(T) \subset E \rightarrow E$ is generalized $\Phi$-pseudo-contractive if $I-T$ is generalized $\phi$-accretive.

O2013 Wang and Liu; licensee Springer. This is an Open Access article distributed under the terms of the Creative Commons Attribution License (http://creativecommons.org/licenses/by/2.0), which permits unrestricted use, distribution, and reproduction in any medium, provided the original work is properly cited. 
Remark 1.3 Definition 1.1 and Definition 1.2 do not assume that $\phi(r)(\Phi(r))$ is strictly increasing. Clearly, $\phi$-strongly accretive maps ( $\phi$-strongly pseudo-contractive maps) are generalized by generalized $\phi$-accretive maps (generalized $\Phi$-pseudo-contractive maps) with $\Phi(r)=r \phi(r)$.

Definition 1.4 $T: D(T) \subset E \rightarrow E$ is called a generalized $\Phi$-accretive type mapping if there exists $x^{*} \in D(T)$ such that for all $x \in D(T)$, there exists $j\left(x-x^{*}\right) \in J\left(x-x^{*}\right)$ such that

$$
\left\langle T x-T x^{*}, j\left(x-x^{*}\right)\right| \geq \Phi\left(\left\|x-x^{*}\right\|\right)
$$

where $\Phi$ is as in Definition 1.2. T is called a generalized $\Phi$-pseudo-contractive type mapping if $I-T$ is a generalized $\Phi$-accretive type mapping.

Recently, Chidume and Chidume proved the following theorems by using the conclusion that a uniformly continuous mapping on $K$ is bounded.

Theorem CC1 [3] Let $E$ be a real normed linear space, $K$ be a nonempty subset of $E$ and $T: K \rightarrow E$ be a uniformly continuous generalized $\Phi$-hemi-contractive mapping, i.e., there exist $x^{*} \in K$ and a strictly increasing function $\Phi:[0, \infty) \rightarrow[0, \infty), \Phi(0)=0$ such that for all $x \in K$, there exists $j\left(x-x^{*}\right) \in J\left(x-x^{*}\right)$ such that

$$
\left\langle T x-T x^{*}, j\left(x-x^{*}\right)\right\rangle \leq\left\|x-x^{*}\right\|^{2}-\Phi\left(\left\|x-x^{*}\right\|\right) .
$$

(a) If $y^{*} \in K$ is a fixed point of $T$, then $y^{*}=x^{*}$ and so $T$ has at most one fixed point in $K$.

(b) Suppose that there exists $x_{0} \in K$ such that the sequence $\left\{x_{n}\right\}$ defined by

$$
x_{n+1}=a_{n} x_{n}+b_{n} T x_{n}+c_{n} u_{n}, \quad \forall n \geq 0,
$$

is contained in $K$, where $\left\{a_{n}\right\},\left\{b_{n}\right\}$ and $\left\{c_{n}\right\}$ are real sequences in $[0,1]$ satisfying the following conditions:

(i) $a_{n}+b_{n}+c_{n}=1$

(ii) $\sum_{n=0}^{\infty}\left(b_{n}+c_{n}\right)=\infty$;

(iii) $\sum_{n=0}^{\infty}\left(b_{n}+c_{n}\right)^{2}<\infty$;

(iv) $\sum_{n=0}^{\infty} c_{n}<\infty$; and $\left\{u_{n}\right\}$ is a bounded sequence in $K$.

Then $\left\{x_{n}\right\}$ converges strongly to $x^{*}$. In particular, if $y^{*}$ is a fixed point of $T$ in $K$, then $\left\{x_{n}\right\}$ converges strongly to $y^{*}$.

Theorem CC2 [3] Let E be a real normed linear space, $A: E \rightarrow E$ be a uniformly continuous generalized $\Phi$-quasi-contractive mapping, i.e., there exists $x^{*} \in D(A)$ such that for all $x \in E$, there exist $j\left(x-x^{*}\right) \in J\left(x-x^{*}\right)$ and a strictly increasing function $\Phi:[0, \infty) \rightarrow[0, \infty)$, $\Phi(0)=0$ such that

$$
\left\langle A x-A x^{*}, j\left(x-x^{*}\right)\right\rangle \geq \Phi\left(\left\|x-x^{*}\right\|\right) .
$$

For arbitrary $x_{0} \in D(A)$, define the sequence $\left\{x_{n}\right\}$ iteratively by

$$
x_{n+1}=a_{n} x_{n}+b_{n} S x_{n}+c_{n} u_{n}, \quad \forall n \geq 0,
$$


where $S: E \rightarrow E$ is defined by $S x:=x-A x$ for all $x \in E$; and $\left\{a_{n}\right\},\left\{b_{n}\right\},\left\{c_{n}\right\}$ are real sequences in $[0,1]$ satisfying the following conditions:

(i) $a_{n}+b_{n}+c_{n}=1$;

(ii) $\sum_{n=0}^{\infty}\left(b_{n}+c_{n}\right)=\infty$;

(iii) $\sum_{n=0}^{\infty}\left(b_{n}+c_{n}\right)^{2}<\infty$;

(iv) $\sum_{n=0}^{\infty} c_{n}<\infty$; and $\left\{u_{n}\right\}$ is a bounded sequence in $K$.

Then $\left\{x_{n}\right\}$ converges strongly to $x^{*}$.

Remark 1.5 In Theorem $\mathrm{CC} 1$ and Theorem CC2, the condition that $K$ is convex is needed. Since $K \subset E$ is a nonempty subset without assuming that $K$ is convex, then a uniformly continuous mapping $T$ on $K$ is not necessarily bounded. See the following example.

Let $\left\{e_{n}\right\}$ be an orthonormal set of $l^{2}, K=\left\{x \in l^{2} \mid x=t e_{n}+(1-t) e_{n+1}, t \in[0,1]\right\}$. Let $T: K \rightarrow l^{2}$ be a mapping defined by

$$
T x=(n+t) e_{n}+(n+1-t) e_{n+1}, \quad \text { where } x=t e_{n}+(1-t) e_{n+1} \in K .
$$

Then $T$ is uniformly continuous on a bounded and nonconvex set $K$. But $T$ is not bounded.

Proof Clearly $K$ is bounded and nonconvex. Let $x_{m}, y_{m} \in K$ such that $\left\|x_{m}-y_{m}\right\| \rightarrow 0$ $(m \rightarrow \infty)$. Then this implies that there exist $n_{0} \in N$ and $t_{m}, t_{m}^{\prime} \in[0,1]$ such that

$$
\begin{aligned}
& x_{m}=t_{m} e_{n_{0}}+\left(1-t_{m}\right) e_{n_{0}+1}, \\
& y_{m}=t_{m}^{\prime} e_{n_{0}}+\left(1-t_{m}^{\prime}\right) e_{n_{0}+1}, \\
& \left\|t_{m}-t_{m}^{\prime}\right\| \rightarrow 0 .
\end{aligned}
$$

So,

$$
\begin{aligned}
\left\|T x_{m}-T y_{m}\right\| & =\left\|\left(n_{0}+t_{m}\right) e_{n_{0}}+\left(n_{0}+1-t_{m}\right) e_{n_{0}+1}-\left(n_{0}+t_{m}^{\prime}\right) e_{n_{0}}-\left(n_{0}+1-t_{m}^{\prime}\right) e_{n_{0}+1}\right\| \\
& =\left|t_{m}-t_{m}^{\prime}\right|\left\|e_{n_{0}}+e_{n_{0}+1}\right\| \\
& =\sqrt{2}\left|t_{m}-t_{m}^{\prime}\right| \rightarrow 0 \quad(m \rightarrow \infty) .
\end{aligned}
$$

Hence $T$ is uniformly continuous.

Let $x \in K$, then

$$
\begin{aligned}
\|T x\| & =\left\|(n+t) e_{n}+(n+1-t) e_{n+1}\right\| \\
& =\left((n+t)^{2}+(n+1-t)^{2}\right)^{\frac{1}{2}} \rightarrow \infty \quad(n \rightarrow \infty) .
\end{aligned}
$$

This says that $T$ is unbounded and completes the proof.

In 1999, Morales and Chidume proved the following theorem.

Theorem MC [1] Let E be a uniformly smooth Banach space, and let $A: E \rightarrow E$ be a bounded demicontinuous $\phi$-strongly accretive mapping for some $x_{0} \in E, \liminf _{r \rightarrow \infty} \phi(r)>$ $\left\|A x_{0}\right\|$. Let $\left\{c_{n}\right\}$ be a real sequence in $[0,1]$ satisfying the following conditions: (i) $\sum_{n=0}^{\infty} c_{n}=$ 
$\infty$; (ii) $\sum_{n=0}^{\infty} c_{n} b\left(c_{n}\right)<\infty$. Let $\left\{x_{n}\right\}$ be a sequence generated by

$$
x_{n+1}=x_{n}-c_{n} A x_{n}, \quad \forall n \geq 0 .
$$

Then there exists a constant $r_{0}>0$ such that when $c_{n}<r_{0}(\forall n \geq 0)$, the sequence $\left\{x_{n}\right\}$ converges strongly to the unique zero of $A$.

Inspired and motivated by these facts, we will give convergence theorems for a fixed point of the generalized $\Phi$-pseudo-contractive type mapping. Our result generalizes the corresponding results in [1-9].

\section{Main results}

Let $F(T)=\{x \in K: T x=x\}, N(A)=\{x \in D(A): A x=0\}$.

We shall make use of the following well-known inequality.

Lemma 2.1 Let E be a real normed linear space. Then the following inequality holds:

$$
\|x+y\|^{2} \leq\|x\|^{2}+2\langle y, j(x+y)\rangle, \quad \forall x, y \in E, \forall j(x+y) \in J(x+y) .
$$

Theorem 2.2 Let $E$ be a real normed linear space, $K$ be a nonempty subset of $E$ and $T$ : $K \rightarrow E$ be a uniformly continuous generalized $\Phi$-pseudo-contractive type mapping, i.e., there exist $x^{*} \in K$ and a function $\Phi:[0, \infty) \rightarrow[0, \infty), \Phi(0)=0$ such that for all $x \in K$, there exists $j\left(x-x^{*}\right) \in J\left(x-x^{*}\right)$ such that

$$
\left\langle T x-T x^{*}, j\left(x-x^{*}\right)\right\rangle \leq\left\|x-x^{*}\right\|^{2}-\Phi\left(\left\|x-x^{*}\right\|\right) .
$$

(a) If $y^{*} \in K$ is a fixed point of $T$, then $y^{*}=x^{*}$ and so $T$ has at most one fixed point in $K$.

(b) Let the above $x^{\star} \in F(T), x_{0} \in K, T x_{0} \neq x_{0}, x_{0} \neq x^{*}$. Suppose that the sequence $\left\{x_{n}\right\}$ defined by

$$
x_{n+1}=a_{n} x_{n}+b_{n} T x_{n}+c_{n} u_{n}, \quad \forall n \geq 0,
$$

is contained in $K$, where $\left\{u_{n}\right\}$ is a bounded sequence in $K$ and $\left\{a_{n}\right\},\left\{b_{n}\right\},\left\{c_{n}\right\}$ are real sequences in $[0,1]$ satisfying the following conditions:

(i) $a_{n}+b_{n}+c_{n}=1$;

(ii) $\sum_{n=0}^{\infty}\left(b_{n}+c_{n}\right)=\infty$;

(iii) $b_{n}+c_{n} \rightarrow 0$ as $n \rightarrow \infty$;

(iv) $c_{n} \leq b_{n}^{2}$.

If $\liminf _{r \rightarrow \infty} \frac{\Phi(r)}{1+r}>\left\|x_{0}-T x_{0}\right\|$ and $\left\{x_{n}-T x_{n}\right\}$ is bounded, then there exists a constant $d_{0}>0$ such that when $0<b_{n}+c_{n} \leq d_{0}$, the sequence $\left\{x_{n}\right\}$ converges strongly to $x^{*}$.

Proof The proof of (a) is the same as the proof of Theorem CC1 [3].

(b) Define $a=\sup \left\{r \in R^{+}: \frac{\Phi(r)}{1+r} \leq\left\|x_{0}-T x_{0}\right\|\right\}$. Then, by $\Phi(0)=0$ and $\left\|x_{0}-T x_{0}\right\|>0$, we have $a>0$. We show that $a \neq \infty$. If $a=\infty$, then there exists $\left\{r_{n}\right\} \subset[0, \infty), r_{n} \rightarrow \infty$ as $n \rightarrow \infty, \frac{\Phi\left(r_{n}\right)}{1+r_{n}} \leq\left\|x_{0}-T x_{0}\right\|$, and hence $\left\|x_{0}-T x_{0}\right\|<\liminf _{r \rightarrow \infty} \frac{\Phi(r)}{1+r} \leq\left\|x_{0}-T x_{0}\right\|$, a contradiction. Therefore, $a<\infty$.

Let $N^{*}=\sup _{n}\left\|u_{n}-x^{*}\right\|$ and $M=\sup _{n}\left\|x_{n}-T x_{n}\right\|+N^{*}$. Since $T$ is uniformly continuous on $K$, for $\epsilon=\frac{\left\|x_{0}-T x_{0}\right\|}{6 a}$, there exists $\delta>0$ such that $x, y \in K$ implies $\|T x-T y\|<\epsilon$. 
Let

$$
d_{0}=\frac{1}{2(a+M)} \min \left\{\delta, a, \frac{\left\|x_{0}-T x_{0}\right\|}{24 a}\right\} .
$$

Claim $1\left\{x_{n}\right\}$ is bounded, i.e.,

$$
\left\|x_{n}-x^{*}\right\| \leq 2 a, \quad \forall n \geq 0
$$

We show this by induction. By (2.1),

$$
\frac{\Phi\left(\left\|x_{0}-x^{*}\right\|\right)}{1+\left\|x_{0}-x^{*}\right\|} \leq\left\|x_{0}-T x_{0}\right\| .
$$

Therefore, $\left\|x_{0}-x^{*}\right\| \leq a<2 a$. Suppose $\left\|x_{n}-x^{*}\right\| \leq 2 a$, we show that $\left\|x_{n+1}-x^{*}\right\| \leq 2 a$. Suppose not, then $\left\|x_{n+1}-x^{*}\right\|>2 a>a$ and from the definition of $a$, we have

$$
\frac{\Phi\left(\left\|x_{n+1}-x^{*}\right\|\right)}{1+\left\|x_{n+1}-x^{*}\right\|}>\left\|x_{0}-T x_{0}\right\|,
$$

and hence

$$
\Phi\left(\left\|x_{n+1}-x^{*}\right\|\right)>\left\|x_{0}-T x_{0}\right\| .
$$

Set $\alpha_{n}=b_{n}+c_{n}$. Then Eq. (2.2) becomes

$$
x_{n+1}=\left(1-\alpha_{n}\right) x_{n}+\alpha_{n} T x_{n}+c_{n} U_{n},
$$

where $U_{n}=u_{n}-T x_{n}$. Observe that

$$
\left\|U_{n}\right\| \leq\left\|u_{n}-x^{*}\right\|+\left\|x_{n}-x^{*}\right\|+\left\|x_{n}-T x_{n}\right\| \leq 2 a+M .
$$

Furthermore,

$$
\begin{aligned}
\left\|x_{n+1}-x^{*}\right\| & \leq\left\|x_{n}-x^{*}\right\|+\alpha_{n}\left\|x_{n}-T x_{n}\right\|+c_{n}\left\|U_{n}\right\| \\
& \leq 2 a+d_{0}(2 a+2 M) \leq 3 a .
\end{aligned}
$$

Also,

$$
\begin{aligned}
\left\|x_{n+1}-x_{n}\right\| & \leq \alpha_{n}\left\{\left\|x_{n}-T x_{n}\right\|+\left\|U_{n}\right\|\right\} \\
& \leq \alpha_{n}(2 a+2 M)<d_{0}(2 a+2 M) \leq \delta,
\end{aligned}
$$

so that $\left\|T x_{n+1}-T x_{n}\right\|<\epsilon$. Using Lemma 2.1, (2.1), (2.3), (2.5), (2.7)-(2.9) and recursion formula (2.6), we now obtain the following estimates:

$$
\begin{aligned}
\left\|x_{n+1}-x^{*}\right\|^{2} & =\left\|x_{n}-x^{*}-\alpha_{n}\left(x_{n}-T x_{n}\right)+c_{n} U_{n}\right\|^{2} \\
& \leq\left\|x_{n}-x^{*}\right\|^{2}-2 \alpha_{n}\left(x_{n}-T x_{n}, j\left(x_{n+1}-x^{*}\right)\right\rangle+2 c_{n}\left\|U_{n}\right\| \cdot\left\|x_{n+1}-x^{*}\right\|
\end{aligned}
$$




$$
\begin{aligned}
\leq & \left\|x_{n}-x^{*}\right\|^{2}-2 \alpha_{n}\left\langle x_{n+1}-T x_{n+1}-x_{n+1}+T x_{n+1}+x_{n}-T x_{n}, j\left(x_{n+1}-x^{*}\right)\right\rangle \\
& +6 c_{n}(2 a+M) a \\
\leq & \left\|x_{n}-x^{*}\right\|^{2}-2 \alpha_{n} \Phi\left(\left\|x_{n+1}-x^{*}\right\|\right)+2 \alpha_{n}\left\|x_{n+1}-x_{n}\right\| \cdot\left\|x_{n+1}-x^{*}\right\| \\
& +2 \alpha_{n}\left\|T x_{n+1}-T x_{n}\right\| \cdot\left\|x_{n+1}-x^{*}\right\|+6 \alpha_{n}^{2}(2 a+M) a \\
\leq & \left\|x_{n}-x^{*}\right\|^{2}-2 \alpha_{n}\left\|x_{0}-T x_{0}\right\|+2 \alpha_{n}^{2}(2 a+2 M) \cdot 3 a+2 \alpha_{n} \cdot \frac{3 a\left\|x_{0}-T x_{0}\right\|}{6 a} \\
& +6 \alpha_{n}^{2}(2 a+M) a \\
\leq & \left\|x_{n}-x^{*}\right\|^{2}-\frac{\alpha_{n}}{2}\left\|x_{0}-T x_{0}\right\|<\left\|x_{n}-x^{*}\right\|^{2},
\end{aligned}
$$

and hence $\left\|x_{n+1}-x^{*}\right\|<2 a$, a contraction. Hence $\left\{x_{n}\right\}$ is bounded.

Claim $2 \liminf _{n \rightarrow \infty}\left\|x_{n}-x^{*}\right\|=0$.

Suppose this is not true. Let $\liminf _{n \rightarrow \infty}\left\|x_{n}-x^{*}\right\|=\sigma>0$. Then there exists an integer $N_{0}$ such that

$$
\left\|x_{n}-x^{*}\right\| \geq \frac{\sigma}{2}, \quad \forall n \geq N_{0}
$$

Since, for any $r_{0}>0, \liminf _{r \rightarrow r_{0}} \Phi(r)>0$, then $\liminf _{n \rightarrow \infty} \Phi\left(\left\|x_{n}-x^{*}\right\|\right) \triangleq \beta>0$. Hence there exists an integer $N_{1}>N_{0}$ such that

$$
\Phi\left(\left\|x_{n}-x^{*}\right\|\right) \geq \frac{\beta}{2}, \quad \forall n \geq N_{1}
$$

Since $\left\{x_{n}-T x_{n}\right\},\left\{u_{n}\right\}$ and $\left\{x_{n}\right\}$ are bounded,

$$
\left\|x_{n+1}-x_{n}\right\| \leq \alpha_{n}\left\|x_{n}-T x_{n}\right\|+c_{n}\left\|u_{n}-T x_{n}\right\| \rightarrow 0 \quad \text { as } n \rightarrow \infty
$$

Therefore, there exists an integer $N_{2}>N_{1}$ such that

$$
\left\|x_{n+1}-x_{n}\right\|<\frac{\beta}{16 a}, \quad \forall n>N_{2} .
$$

Since $T$ is uniformly continuous, then there exists an integer $N_{3}>N_{2}$ such that

$$
\left\|T x_{n+1}-T x_{n}\right\|<\frac{\beta}{16 a}, \quad \forall n>N_{3} .
$$

Also, since $\alpha_{n} \rightarrow 0$ as $n \rightarrow \infty$, there exists an integer $N_{4}>N_{3}$ such that

$$
\alpha_{n}<\frac{\beta}{16 a(2 a+M)}, \quad \forall n>N_{4} .
$$

By Lemma and (2.11)-(2.14), we obtain the following estimates:

$$
\begin{aligned}
\left\|x_{n+1}-x^{*}\right\|^{2} & \leq\left\|x_{n}-x^{*}\right\|^{2}-2 \alpha_{n}\left\langle x_{n}-T x_{n}, j\left(x_{n+1}-x^{*}\right)\right\rangle+2 c_{n}\left\langle U_{n}, j\left(x_{n+1}-x^{*}\right)\right\rangle \\
& \leq\left\|x_{n}-x^{*}\right\|^{2}-2 \alpha_{n} \Phi\left(\left\|x_{n+1}-x^{*}\right\|\right)+2 \alpha_{n}\left\|x_{n+1}-x_{n}\right\| \cdot\left\|x_{n+1}-x^{*}\right\|
\end{aligned}
$$




$$
\begin{aligned}
& +2 \alpha_{n}\left\|T x_{n+1}-T x_{n}\right\| \cdot\left\|x_{n+1}-x^{*}\right\|+2 \alpha_{n}^{2}(2 a+M)\left\|x_{n+1}-x^{*}\right\| \\
\leq & \left\|x_{n}-x^{*}\right\|^{2}-2 \alpha_{n} \cdot \frac{\beta}{2}+2 \alpha_{n} \cdot \frac{\beta}{16 a} \cdot 2 a+2 \alpha_{n} \cdot \frac{\beta}{16 a} \cdot 2 a \\
& +2 \alpha_{n} \cdot \frac{\beta}{16 a(2 a+M)} \cdot(2 a+M) \cdot 2 a \\
= & \left\|x_{n}-x^{*}\right\|^{2}-\frac{1}{4} \alpha_{n} \beta
\end{aligned}
$$

for all $n \geq N_{4}$, and this implies $\sum_{n=0}^{\infty} \alpha_{n}<\infty$, a contraction to condition (ii) of Theorem 2.2. Hence Claim 2 holds.

Thus, there exists a subsequence $\left\{x_{n_{j}}\right\}$ such that $x_{n_{j}} \rightarrow x^{*}$ as $n \rightarrow \infty$, i.e., for any $\epsilon>0$, there exists some integer $n_{j_{0}}$ such that $\left\|x_{n_{j_{0}}}-x^{*}\right\|<\epsilon$.

Claim $3\left\|x_{n_{j_{0}+m}}-x^{*}\right\|<\epsilon, m=1,2, \ldots$

Let $r_{0}=\inf \{\Phi(r): r \geq \epsilon\}$, then $r_{0}>0$.

Since $\left\|x_{n+1}-x_{n}\right\| \rightarrow 0,\left\|T x_{n+1}-T x_{n}\right\| \rightarrow 0$ and $\alpha_{n} \rightarrow 0$ as $n \rightarrow \infty$, then there exists an integer $N>0$ such that for all $n \geq N$, the following inequalities hold:

$$
\begin{aligned}
& \left\|x_{n+1}-x_{n}\right\| \leq \frac{r_{0}}{16 a}, \\
& \left\|T x_{n+1}-T x_{n}\right\| \leq \frac{r_{0}}{16 a}, \\
& \alpha_{n}<\frac{r_{0}}{4 a(2 a+M)} .
\end{aligned}
$$

If $\left\|x_{n_{j_{0}+1}}-x^{*}\right\| \geq \epsilon$, then $\Phi\left(\left\|x_{n_{j_{0}}+1}-x^{*}\right\|\right) \geq r_{0}$. Using recursion formula (2.15), we obtain the following estimate:

$$
\begin{aligned}
\left\|x_{n_{j_{0}}+1}-x^{*}\right\|^{2} \leq & \left\|x_{n_{j_{0}}}-x^{*}\right\|^{2}-2 \alpha_{n} r_{0}+2 \alpha_{n} \cdot \frac{r_{0}}{16 a} \cdot 2 a+2 \alpha_{n} \cdot \frac{r_{0}}{16 a} \cdot 2 a \\
& +2 \alpha_{n} \cdot \frac{r_{0}}{4 a(2 a+M)} \cdot(2 a+M) \cdot 2 a \\
= & \left\|x_{n_{j 0}}-x^{*}\right\|^{2}-\alpha_{n} r_{0}+\frac{1}{2} \alpha_{n} r_{0} \\
= & \left\|x_{n_{j_{0}}}-x^{*}\right\|^{2}-\frac{1}{2} \alpha_{n} r_{0}<\left\|x_{n_{j_{0}}}-x^{*}\right\|^{2}<\epsilon,
\end{aligned}
$$

a contradiction. Hence Claim 3 holds for $m=1$. Assume now that it holds for $m=k$. From the above argument, one easily proves that it holds for $m=k+1$. Hence, Claim 3 holds. This shows that $\left\{x_{n}\right\}$ converges strongly to $x^{*}$ as $n \rightarrow \infty$, completing the proof of Theorem 2.2.

Theorem 2.3 Let E be a real normed linear space, and let $A: D(A) \subset E \rightarrow$ E be a uniformly continuous generalized $\Phi$-accretive type mapping, i.e., there exists $x^{*} \in N(A)$ such that for all $x \in E$, there exist $j\left(x-x^{*}\right) \in J\left(x-x^{*}\right)$ and a function $\Phi:[0, \infty) \rightarrow[0, \infty), \Phi(0)=0$ such that

$$
\left\langle A x-A x^{*}, j\left(x-x^{*}\right)\right\rangle \geq \Phi\left(\left\|x-x^{*}\right\|\right) .
$$


For arbitrary $x_{0} \in D(A)$, define the sequence $\left\{x_{n}\right\}$ iteratively by

$$
x_{n+1}=a_{n} x_{n}+b_{n} S x_{n}+c_{n} u_{n}, \quad \forall n \geq 0,
$$

where $S: E \rightarrow E$ is defined by $S x:=x-A x$ for all $x \in D(A)$; and $\left\{u_{n}\right\}$ is a bounded sequence in $E,\left\{a_{n}\right\},\left\{b_{n}\right\},\left\{c_{n}\right\}$ are real sequences in $[0,1]$ satisfying the following conditions:

(i) $a_{n}+b_{n}+c_{n}=1$

(ii) $\sum_{n=0}^{\infty}\left(b_{n}+c_{n}\right)=\infty$;

(iii) $b_{n}+c_{n} \rightarrow 0$ as $n \rightarrow \infty$;

(iv) $c_{n} \leq b_{n}^{2}$.

If $\liminf _{r \rightarrow \infty} \frac{\Phi(r)}{1+r}>\left\|A x_{0}\right\|$ and $\left\{A x_{n}\right\}$ is bounded, then there exists a constant $d_{0}>0$ such that when $0<b_{n}+c_{n} \leq d_{0}$, the sequence $\left\{x_{n}\right\}$ converges strongly to $x^{*}$.

Proof We simply observe that $S$ is a uniformly continuous and generalized $\Phi$-pseudocontractive type mapping of $D(A)$ into $E$. The result can follow from Theorem 2.2.

Remark 2.4 (1) Our theorems extend and improve Theorem CC1 and Theorem CC2 in the following ways:

(i) Our theorems do not assume that $\Phi(t)$ is a strictly increasing function.

(ii) The conditions $\sum_{n=0}^{\infty}\left(b_{n}+c_{n}\right)^{2}<\infty, \sum_{n=0}^{\infty} c_{n}<\infty$ are replaced by $b_{n}+c_{n} \rightarrow 0$ as $n \rightarrow \infty, c_{n} \leq b_{n}^{2}$, respectively. Our theorems enlarge the range of $b_{n}$ and $c_{n}$ values.

(iii) We do not need the condition that $K$ is convex. We added the condition that $\left\{x_{n}-T x_{n}\right\}$ is bounded. It is readily seen that $\left\{x_{n}\right\}$ converges strongly to $x^{*}$ if and only if $\left\{x_{n}-T x_{n}\right\}\left(\left\{A x_{n}\right\}\right)$ is bounded under the assumptions of Theorem 2.2 (Theorem 2.3).

(2) Since the class of generalized $\Phi$-accretive maps (generalized $\Phi$-pseudo-contractive maps) includes the class of $\phi$-strongly accretive maps ( $\phi$-strongly pseudo-contractive maps), our results unify and extend many known results. In particular, since $\liminf _{r \rightarrow \infty} \phi(r)>\left\|A x_{0}\right\|$ in Theorem MC implies $\liminf _{r \rightarrow \infty} \frac{\Phi(r)}{1+r}=\liminf _{r \rightarrow \infty} \frac{\phi(r) r}{1+r}=$ $\liminf _{r \rightarrow \infty} \phi(r)>\left\|A x_{0}\right\|$, our Theorem 2.3 extends Theorem MC from uniformly smooth Banach spaces to arbitrary normed linear spaces.

(3) Our results also improve and extend the corresponding results in [2, 4-9].

Competing interests

The authors declare that they have no competing interests.

Authors' contributions

All authors contributed equally and significantly in writing this paper. All authors read and approved the final manuscript.

\section{Author details}

${ }^{1}$ College of Mathematics and statistics, Nanjing University of Information Science and Technology, Nanjing, 210044, P.R. China. ${ }^{2}$ Department of Mathematics, Nanchang University, Jiangxi, 330031, P.R. China.

\section{Acknowledgements}

The authors thank the editor and the referees for constructive and pertinent suggestions. One of authors (Chao Wang) was partially supported by the NSF of China (No. 11126290), University Science Research Project of Jiangsu Province (No. 13KSB110021) and Scholarship Award for Excellent Doctoral Student granted by Ministry of Education (No. 1390219098). 


\section{References}

1. Morales, CE, Chidume, CE: Convergence of the steepest descent method for accretive operators. Proc. Am. Math. Soc. $127,3677-3683(1999)$

2. Jung, JS, Morales, CE: The Mann process for perturbed $m$-accretive operator in Banach spaces. Nonlinear Anal. 46 231-243 (2001)

3. Chidume, $\mathrm{CE}$, Chidume, CO: Convergence theorems for fixed points of uniformly continuous generalized $\phi$-hemi-contractive mappings. J. Math. Anal. Appl. 302, 545-554 (2005)

4. Chidume, CE, Zegeye, $\mathrm{H}$ : Approximation methods for nonlinear operator equations. Proc. Am. Math. Soc. 131, 2467-2478 (2002)

5. Gu, F: Convergence theorems for $\phi$-pseudo-contractive type mapping in normed linear space. Northeast. Math. J. 17, 340-346 (2001)

6. Xue, ZQ, Rafiq, A, Zhou, HY: On the convergence of multistep iteration for uniformly continuous $\Phi$-hemicontractive mappings. Abstr. Appl. Anal. 2012, Article ID 386983 (2012)

7. Thakur, BS, Dewangan, R, Postolache, M: Strong convergence of new iteration process for a strongly continuous semigroup of asymptotically pseudocontractive mappings. Numer. Funct. Anal. Optim. (2013). doi:10.1080/01630563.2013.808667

8. Yao, Y, Postolache, M: Iterative methods for pseudomonotone variational inequalities and fixed point problems. J. Optim. Theory Appl. 155, 273-287 (2012)

9. Yao, Y, Postolache, M, Liou, YC: Coupling Ishikawa algorithms with hybrid techniques for pseudocontractive mappings. Fixed Point Theory Appl. 2013, 211 (2013) (Editorially accepted)

10.1186/1687-1812-2013-311

Cite this article as: Wang and Liu: Convergence theorems for a generalized $\Phi$-pseudo-contractive type mapping in real normal linear spaces. Fixed Point Theory and Applications 2013, 2013:311

\section{Submit your manuscript to a SpringerOpen ${ }^{\circ}$ journal and benefit from:}

- Convenient online submission

- Rigorous peer review

- Immediate publication on acceptance

- Open access: articles freely available online

- High visibility within the field

- Retaining the copyright to your article 